Annales Geophysicae (2001) 19: 59-69 (c) European Geophysical Society 2001

\title{
Sporadic-E associated with the Leonid meteor shower event of November 1998 over low and equatorial latitudes
}

\author{
H. Chandra ${ }^{1}$, S. Sharma ${ }^{1}$, C. V. Devasia ${ }^{2}$, K. S. V. Subbarao ${ }^{2}$, R. Sridharan ${ }^{2}$, J. H. Sastri ${ }^{3}$, and J. V. S. V. Rao ${ }^{3}$ \\ ${ }^{1}$ Physical Research Laboratory, Ahmedabad, India 380009 \\ ${ }^{2}$ Space Physics Laboratory, VSSC, Trivandrum, India 695022 \\ ${ }^{3}$ Indian Institute of Astrophysics, Bangalore, India 560034
}

Received: 21 February 2000 - Revised: 6 October 2000 - Accepted: 20 November 2000

\begin{abstract}
Rapid radio soundings were made over Ahmedabad, a low latitude station during the period 16-20 November 1998 to study the sporadic-E layer associated with the Leonid shower activity using the KEL Aerospace digital ionosonde. Hourly ionograms for the period 11 November to 24 November were also examined during the years from 1994 to 1998. A distinct increase in sporadic-E layer occurrence is noticed on 17, 18 and 19 November from 1996 to 1998. The diurnal variations of $f_{0} \mathrm{E}_{s}$ and $f_{b} \mathrm{E}_{s}$ also show significantly enhanced values for the morning hours of 18 and 19 November 1998. The ionograms clearly show strong sporadic-E reflections at times of peak shower activity with multiple traces in the altitude range of 100-140 km in few ionograms. Sporadic-E layers with multiple structures in altitude are also seen in some of the ionograms (quarter hourly) at Thumba, situated near the magnetic equator. Few of ionograms recorded at Kodaikanal, another equatorial station, also show sporadic-E reflections in spite of the transmitter power being significantly lower. These new results highlighting the effect of intense meteor showers in the equatorial and low latitude E-region are presented.
\end{abstract}

Key words. Ionosphere (equatorial ionosphere) - Radio science (ionospheric physics)

\section{Introduction}

The Leonid meteor shower is known to have strong activity every 33 years, which is the period of the Tempel-Tuttle, the parent comet of the shower. During the last return in 1966, visible meteors with an hourly rate of 140,000-150,000 were reported in the West Coast of America (Milon, 1967). A meteor outburst of Leonids was observed in November 1994 and strong meteor shower was predicted to occur in 1998 or 1999 (Jenniskens, 1996). Though a strong outburst was not expected in 1997, optical meteor observations were made in 1997 by Kinoshita et al. (1999) because the distance between

Correspondence to: H. Chandra (hchandra@prl.ernet.in) the descending node and the parent comet was much smaller in 1997 than in 1998. A strong event of meteor burst with 100-150 meteors in 2 seconds was observed at the time of the descending node of the comet at $1331 \mathrm{~h}$ UT on 17 November 1998. The observed rate was comparable to the maximum hourly rate reported in 1966.

There were several observations planned for the Leonid shower event of November 1998. One of the effects of the meteor showers is the enhanced activity in the formation of sporadic-E layers in ionosphere. Rapid radio soundings were made over Ahmedabad $\left(23.0^{\circ} \mathrm{N}, 72.4^{\circ} \mathrm{E}\right.$, dip $\left.34^{\circ} \mathrm{N}\right)$ to study the effects of the meteor shower on the ionosphere. Ionograms were recorded at an interval of five minutes during the hours from midnight to morning of 17-19 November and every minute from $03-06 \mathrm{~h}$ of 18 November 1998 . Ionograms at Thumba $\left(8.3^{\circ} \mathrm{N}, 76.9^{\circ} \mathrm{E}, \operatorname{dip} 0.6^{\circ} \mathrm{N}\right)$ and Kodaikanal $\left(10.2^{\circ}\right.$ $\left.\mathrm{N}, 77.5^{\circ} \mathrm{E}, \operatorname{dip} 6^{\circ} \mathrm{N}\right)$, located near the magnetic equator were also examined. The sporadic-E layers associated with the Leonid meteor shower event of November 1998 are reported in the present communication.

\section{Results}

The daily mean percentage occurrence of sporadic-E over Ahmedabad is compared for the days from 11 to 24 November of the years 1994 to 1998 from the hourly ionograms and shown in Fig. 1. The percentage occurrences are rather low during the years 1994 and 1995 with values ranging between 15 and $50 \%$ on different days. However there is an increase seen from the year 1996 with daily mean percentage occurrences reaching as high as $80 \%$ on some days. Considering the days 17 to 19 November only, the percentage occurrences are 15, 40 and 40 in 1994; 15, 20 and 50 in 1995; 40, 50, and 35 in 1996; 50, 60 and 20 in 1997 and 75, 80 and 40 in 1998. Thus it appears that there is an increase in the occurrence of sporadic-E in the years 1996 through 1998. We have also examined the occurrence of nighttime sporadic-E (20-06h) and the results are shown in Fig. 2. The occurrence of sporadic-E 


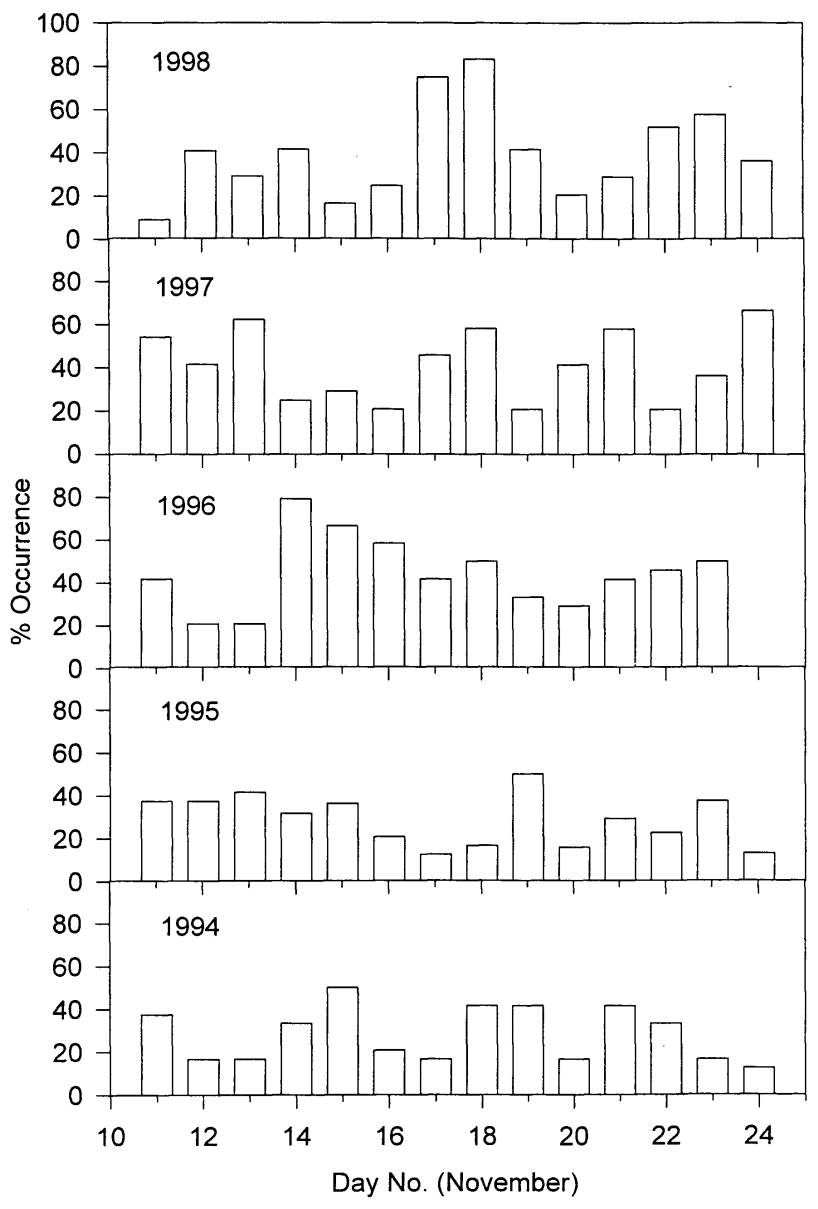

Fig. 1. Daily mean percentage occurrence of sporadic-E over Ahmedabad for the days 11-24, November of years 1994-1998 based on hourly data.

is seen to be higher during the year 1998 especially for the night of 17-18 November. The percentage occurrences for the years 1994 to 1998 for this night are $0,10,38,57$ and 98 respectively. Thus the occurrence of sporadic-E during night hours increases significantly from 1994 to 1998 . Chandra (1978) studied the occurrence of night $\mathrm{E}_{s}$ over Ahmedabad during high, medium and low sunspot years of the period 1958-67 and found the occurrence to be decreasing with increasing solar activity. Therefore one would have expected a decrease in the occurrence frequency of night $\mathrm{E}_{S}$ on account of increasing solar activity from 1994 to 1998 . This fact further strengthens the conclusion that the increase noted in the occurrence of nighttime sporadic-E over Ahmedabad is due to the enhanced meteor shower activity.

The daily variations of the quarter hourly values of $f_{0} \mathrm{E}_{s}$, the critical frequency, for the three days (16-18 November) of the three years 1996 to 1998 are plotted in Fig. 3. The progressive increase in the number of points for the years 1996 to 1998 indicates the increase in the occurrence of sporadicE from the year 1996 to 1998 . There is an increase in the value of $f_{0} \mathrm{E}_{s}$ in the early hours (around $04 \mathrm{~h}$ ) on 18 November 1998. An increase is also seen between 01 and $02 \mathrm{~h}$ of

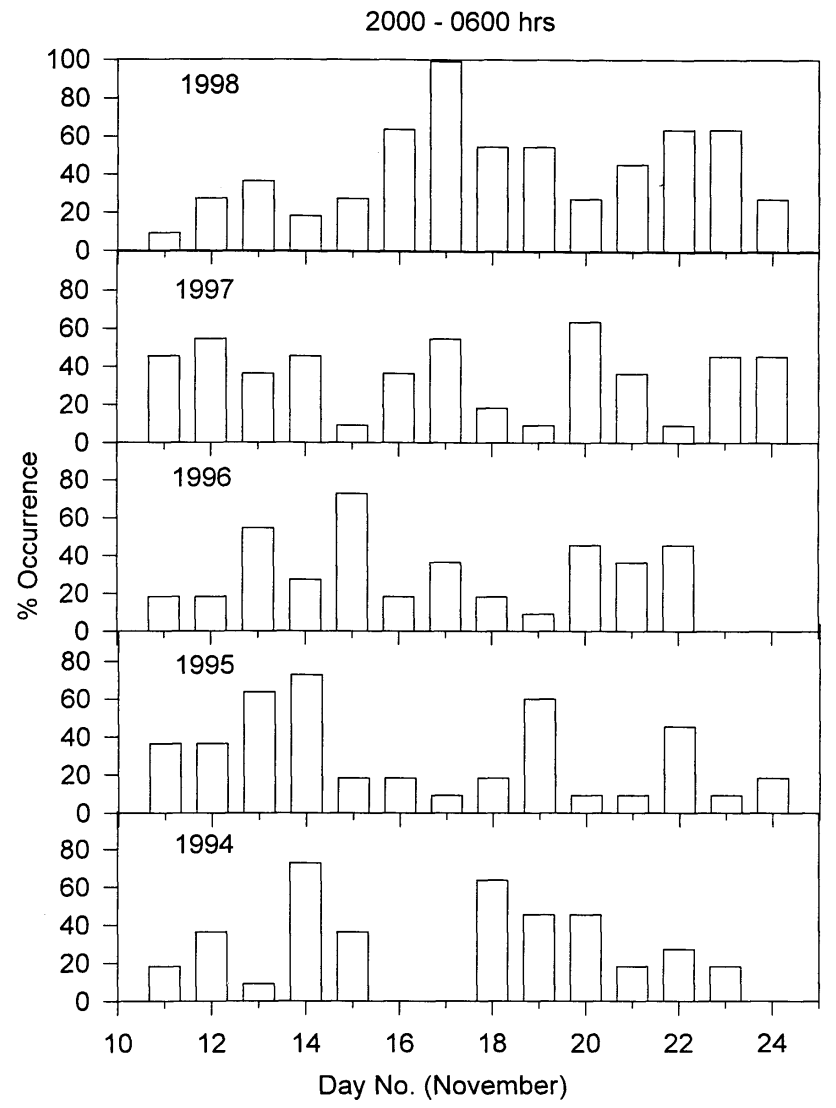

Fig. 2. Mean nighttime (20-06) percentage occurrence of sporadicE over Ahmedabad for the days 11-24, November of years 19941998 based on hourly data.

19 November 1998. The daily variations of $f_{b} \mathrm{E}_{s}$, which is an indicator of the ionization associated with the sporadic-E layer, for the three days are shown in Fig. 4. These are based on hourly ionograms for the years 1996-1997 and quarter hourly ionograms for 1998. There is a clear indication of an increase in the nighttime values of $f_{b} \mathrm{E}_{s}$, during the night 17-18 November 1998. Thus there is evidence for the meteor shower activity enhancing the ionization of sporadic-E layers.

Few selected ionograms recorded over Ahmedabad during the nights of 17-18 November 1998 are reproduced in Figs. 5 , 6. On 17 November sporadic-E first appeared at $0040 \mathrm{~h}$ and lasted for about half an hour. Another sporadic-E patch appeared later at $0120 \mathrm{~h}$ and disappeared at $0145 \mathrm{~h}$. A stronger event started at $0155 \mathrm{~h}$ with two traces, one at $110 \mathrm{~km}$ and the second at $125 \mathrm{~km}$. The trace subsequently was seen at $100 \mathrm{~km}$ at $0230 \mathrm{~h}$. The sporadic-E echoes were seen again from $0300 \mathrm{~h}$ with traces at 110 and $130 \mathrm{~km}$. Multiple traces at altitudes between 100 and $135 \mathrm{~km}$ were seen right through morning with $f_{0} \mathrm{E}_{s}$ exceeding $5 \mathrm{MHz}$ at $0705 \mathrm{~h}$.

During the night of 17-18 November, first trace from sporadic-E was seen at $2356 \mathrm{~h}$ at $115 \mathrm{~km}$ which later appeared at $105 \mathrm{~km}$ as strong multiple reflections $(0129,0145 \mathrm{~h})$. Another patch of strong sporadic-E was seen from $0225 \mathrm{~h}$ till 


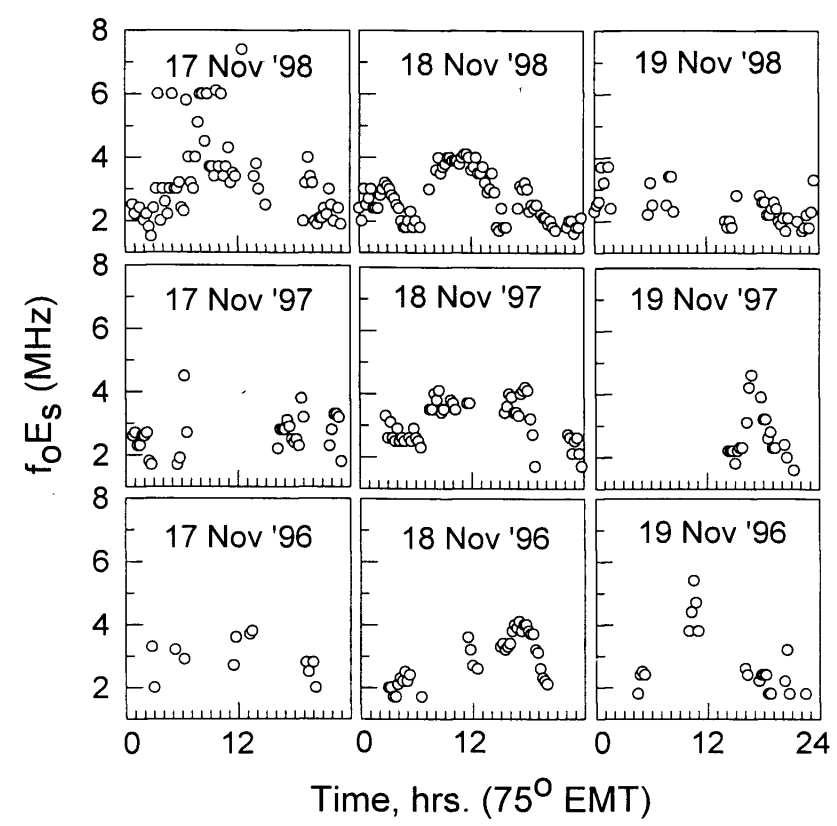

Fig. 3. Daily variations of $f_{0} \mathrm{E}_{s}$ over Ahmedabad for the period 17 to 19 November for the years 1996-98 plotted from the quarter hourly data.

sunrise. Ionograms from 0225 to $0345 \mathrm{~h}$ show strong multiple reflections (up to 5 multiples). The F-region traces are partially blanketed from 0225 to $0420 \mathrm{~h}$, with $f_{b} \mathrm{E}_{s}$ values varying from 2.2 to $3.0 \mathrm{MHz}$ at different times indicating increased ionization. Since the $\mathrm{E}_{s}$ is of blanketing type, the additional stratification seen around $130 \mathrm{~km}$ at $0225 \mathrm{~h}$ has to be necessarily due to oblique echoes. The high order multiples essentially indicate that most of the probing radio wave is reflected straight down by the $\mathrm{E}_{s}$ layer which often is encountered when the layer is thin and sharp with steep gradients. This is consistent with the increase in blanketing frequency. An additional trace appeared at about $130 \mathrm{~km}(0225$ to $0420 \mathrm{~h})$.

Two sequences of ionograms recorded every five minutes over Ahmedabad on 17 November 1998 are shown in Fig. 7. The first sequence shows traces of sporadic-E reflections appearing at 100 and $125 \mathrm{~km}$ on the ionograms at $0155 \mathrm{~h}$ and $0200 \mathrm{~h}$. At $0205 \mathrm{~h}$ there are three traces seen at 100, 115 and $130 \mathrm{~km}$. The reflections from $130 \mathrm{~km}$ are quite strong and even its second multiple is seen. The ionogram at $0210 \mathrm{~h}$ shows yet another trace of reflection at $160 \mathrm{~km}$ while the other three traces are seen at $0215 \mathrm{~h}$ also. The second sequence in Fig. 7 shows sequence of ionograms from $0500 \mathrm{~h}$ to $0545 \mathrm{~h}$ on 17 November 1998 over Ahmedabad. At 0500h there are echoes from $100 \mathrm{~km}$ and $110 \mathrm{~km}$ and very weak trace at $140 \mathrm{~km}$. The ionogram at $0505 \mathrm{~h}$ shows strong echoes from $100 \mathrm{~km}$ and echoes from $130 \mathrm{~km}$ and $155 \mathrm{~km}$ (weak). The reflection at $155 \mathrm{~km}$ is seen at $0510 \mathrm{~h}$ also but the trace at $130 \mathrm{~km}$ has disappeared. At $0515 \mathrm{~h}$ traces are seen at 100, 120 and $130 \mathrm{~km}$ but only one trace at $100 \mathrm{~km}$ is seen at $0520 \mathrm{~h}$. Two traces at 110 and $130 \mathrm{~km}$ are noted at $0525 \mathrm{~h}$

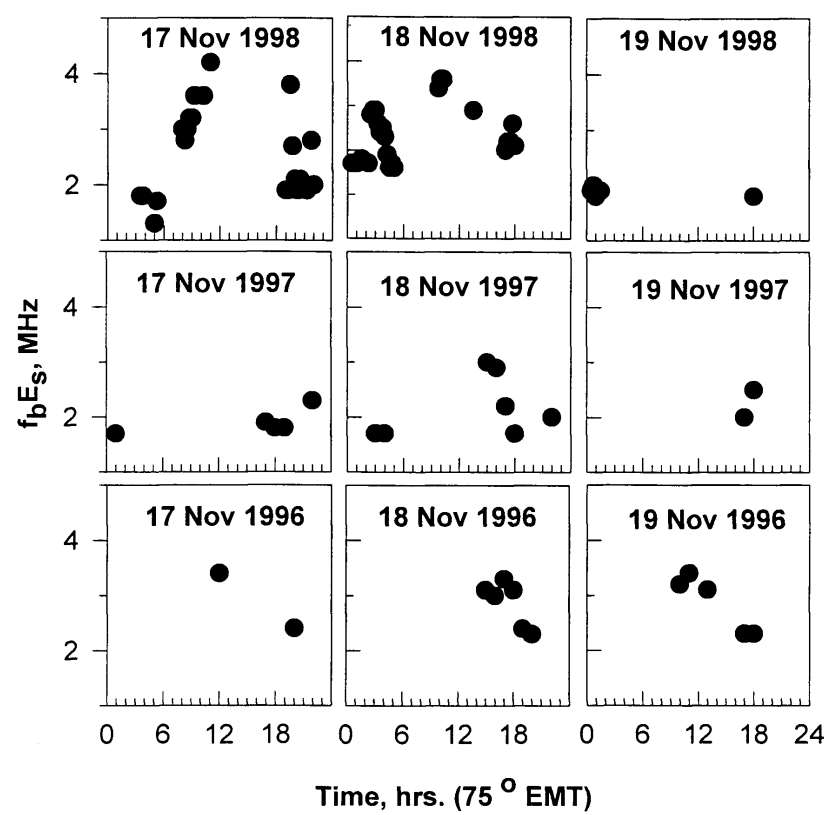

Fig. 4. Daily variations of $f_{b} \mathrm{E}_{s}$ over Ahmedabad for the period 17 to 19 November for the years 1996-98 based on hourly data for 1996-97 and quarter hourly data for 1998.

followed by single broad traces between 100 and $120 \mathrm{~km}$ at $0530 \mathrm{~h}$. Weak reflection from $100 \mathrm{~km}$ and strong reflections from $125 \mathrm{~km}$ are seen at $0535 \mathrm{~h}$ and the ionogram at $0540 \mathrm{~h}$ shows only a single trace from $125 \mathrm{~km}$. Finally the ionogram at $0545 \mathrm{~h}$ shows two traces at $110 \mathrm{~km}$ and $130 \mathrm{~km}$. Thus the echoes are some times stronger from $100 \mathrm{~km}$ while at times the echoes from higher range are stronger than the echoes at $100 \mathrm{~km}$. These characteristics are different from those seen in the normal sporadic-E events and are probably due to the meteoric ionization produced due to bursts of meteors travelling at different velocities. These aspects are discussed later.

We have also examined the ionograms at stations located closer to the dip equator in order to examine the various manifestations of the shower. Few examples of ionograms at Thumba are shown in Figs. 8, 9. On 17 November 1998 sporadic-E traces were seen at $0215 \mathrm{~h}$ around $115 \mathrm{~km}$. The layer is stronger at $0300 \mathrm{~h}$ with $f_{0} \mathrm{E}_{s}$ close to $7 \mathrm{MHz}$. And also there are additional traces at 150 and $160 \mathrm{~km}$. However at $0315 \mathrm{~h}$ there is only a single trace at $135 \mathrm{~km}$ and by 0330 it reduces into a weak layer. Another patch of strong $\mathrm{E}_{S}$ appears at $0345 \mathrm{~h}$ with traces at 115 (exceeding $6 \mathrm{MHz}$ ) and $145 \mathrm{~km}$. The ionogram at $0400 \mathrm{~h}$ is marked with three traces at 110,130 and $155 \mathrm{~km}$. The traces are seen at lower ranges in subsequent ionograms and at $0430 \mathrm{~h}$ seen at $100,110,115$ and $125 \mathrm{~km}$. An additional trace extending up to $8 \mathrm{MHz}$ at $190 \mathrm{~km}$ is also seen at $0430 \mathrm{~h}$. The multiple structure remains up to $0600 \mathrm{~h}$ with four clear traces at 0545 and $0600 \mathrm{~h}$.

On the night of 17-18 November 1998 echoes at 110 and $120 \mathrm{~km}$ appear at $2230 \mathrm{~h}$. This patch is seen up to $2345 \mathrm{~h}$. Later sporadic-E traces were seen at $0315 \mathrm{~h}(110 \mathrm{~km})$ and at $0400 \mathrm{~h}(165 \mathrm{~km})$. Based on these it could be concluded 

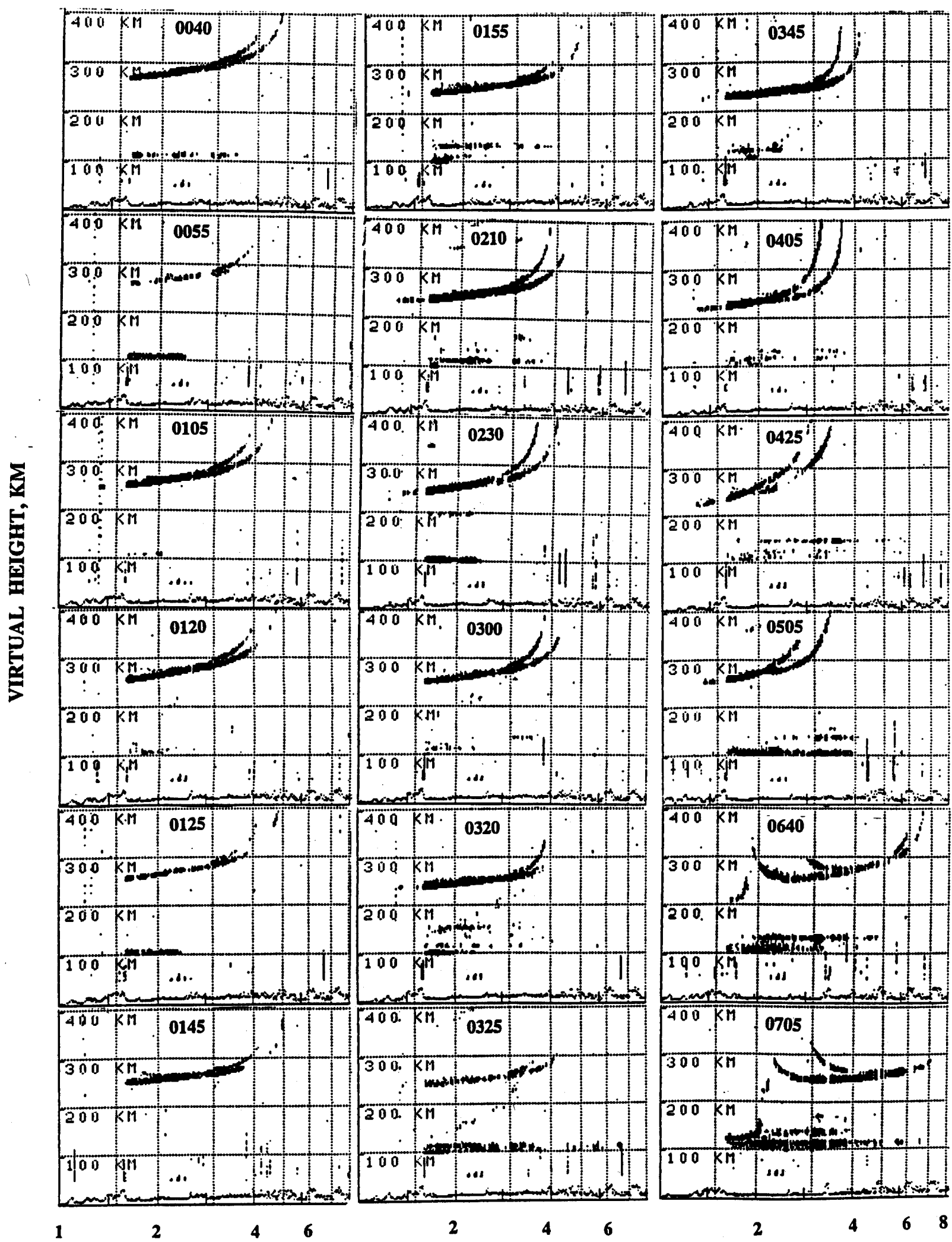

\section{FREQUENCY, MHz}

Fig. 5. Selected ionograms over Ahmedabad from 0040 to $0705 \mathrm{~h}$ of 17 November 1998 showing the development of sporadic-E associated with Leonid shower activity. 


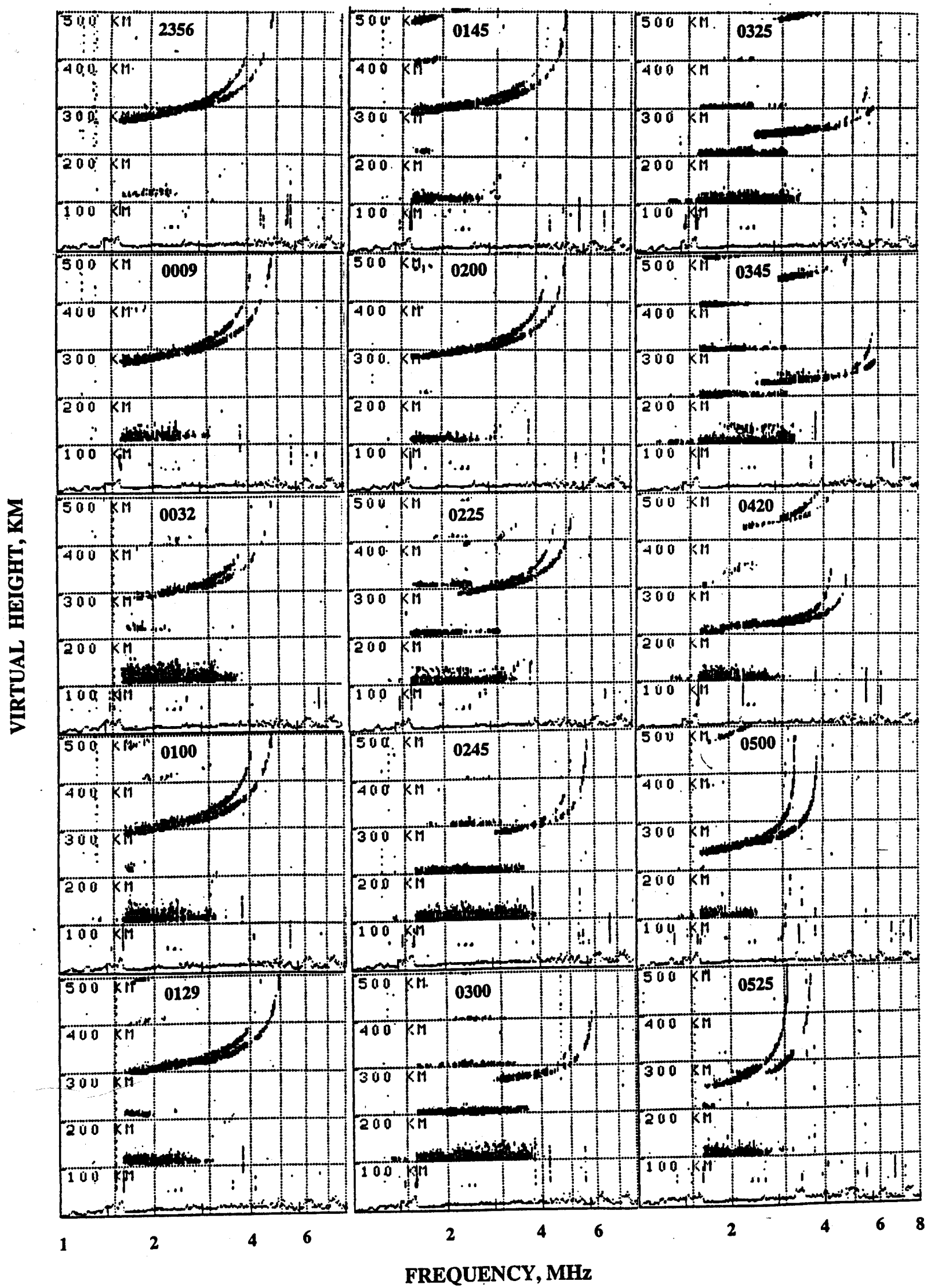

Fig. 6. Selected ionograms over Ahmedabad during the night 17-18 November 1998 showing the development of sporadic-E associated with Leonid shower activity. 

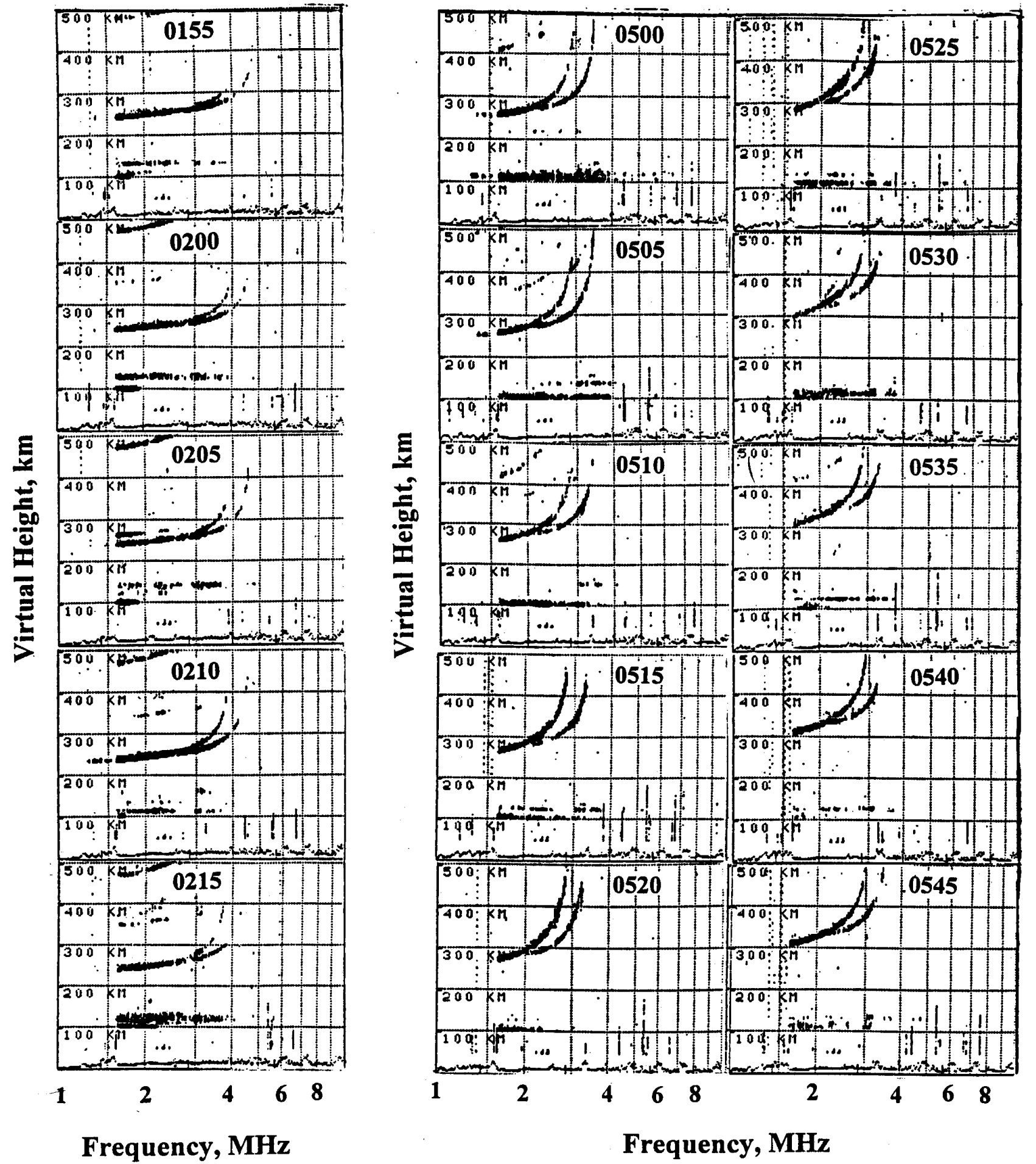

Fig. 7. Two sequences of ionograms at 5 minutes interval over Ahmedabad from 0155 to $0215 \mathrm{~h}$ and from 0500 to $0545 \mathrm{~h}$ of $17 \mathrm{November}$ 1998 showing the development of sporadic-E associated with Leonid shower activity.

that the sporadic-E layers at Thumba were also associated with meteor shower activity but showed distinctly different characteristics. The ionograms at Kodaikanal situated near the dip equator did not indicate any sporadic-E layers during the night of 16- 17 November 1998. However there were
sporadic-E layers seen in few ionograms of 18 November (0115, 0130 and 0145h) and on 19 November 1998 (0130, 0215 and $0245 \mathrm{~h}$ ). It must be noted that the ionosonde at Kodaikanal was functioning with low transmitter power during November 1998. The variations with time of $f_{0} \mathrm{E}_{s}$ at the 


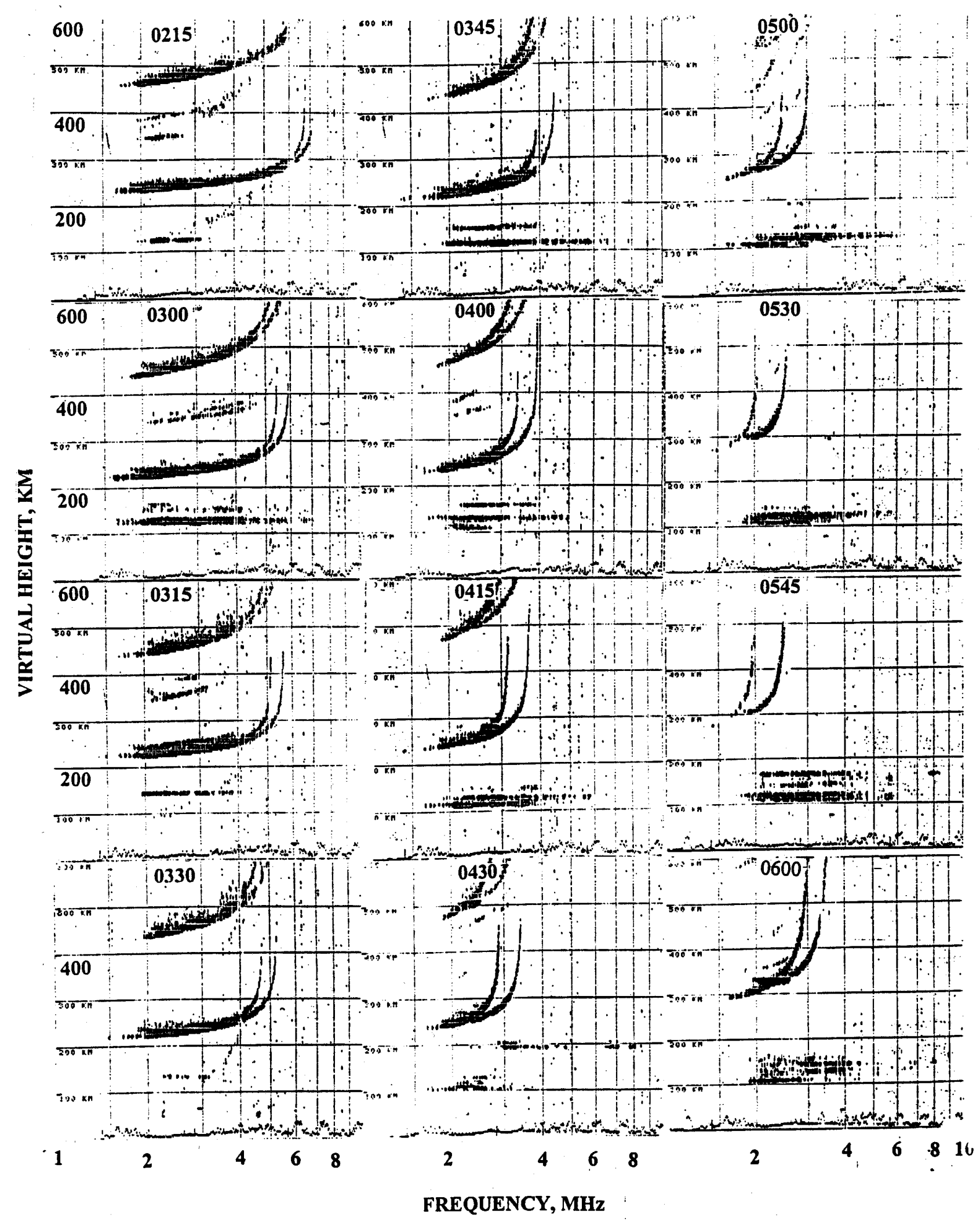

Fig. 8. Selected ionograms over Thumba from $0215 \mathrm{~h}$ to $0600 \mathrm{~h}$ of 17 November 1998 showing the development of sporadic-E associated with Leonid shower activity. 


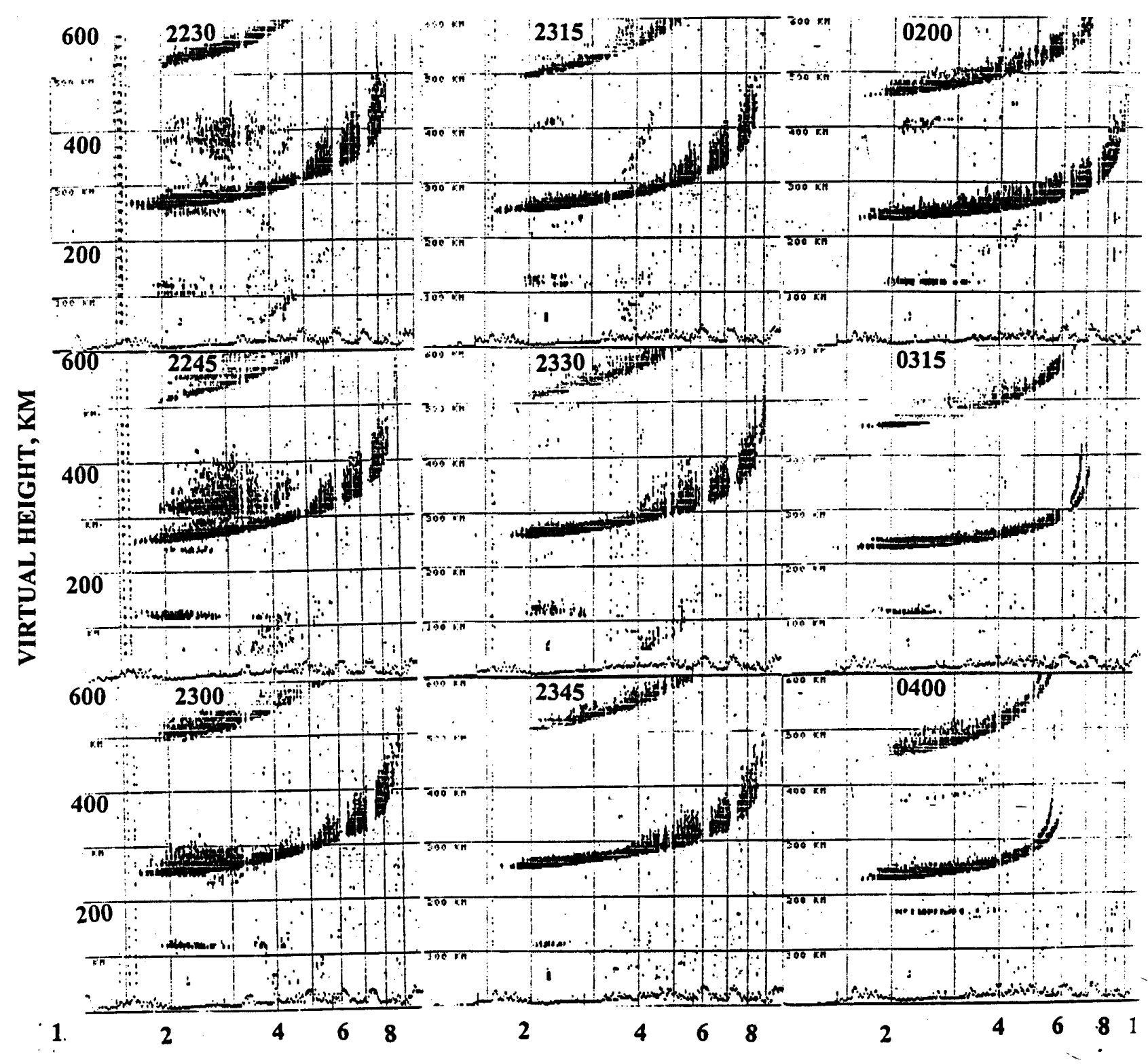

FREQUENCY, MHz

Fig. 9. Selected ionograms over Thumba during the night of 17-18 November 1998 showing the development of sporadic-E associated with Leonid shower activity.

three locations Ahmedabad, Thumba and Kodaikanal during the period 17-19 November 1998 based on quarter hourly ionograms is shown in Fig. 10. High values of $f_{0} \mathrm{E}_{s}$ are seen at Kodaikanal at 0115-0145h on 18 November 1998.

\section{Discussion}

Quite a few studies have been carried out in the past on the possible correlation of meteoric activity with the sporadicE layers seen usually in the ionograms. Short-lived echoes were often noticed from the E-region from the night-time radio soundings. Schafer and Goodall (1932) reported as- sociation of the intermittent $\mathrm{E}_{S}$ echoes at altitudes between 100 and $200 \mathrm{~km}$ with the Leonid meteor showers. Appleton and Naismith (1947) reported longer- duration sporadicE during periods of shower activity. Ellyet and Goldsborough (1976) and Whitehead (1970) have summarized the results on the contribution of metallic ions in the formation of sporadic-E. Ellyet and Goldsborough (1976) have further studied the relationship of meteors to sporadic-E and identified three classes of meteor produced sporadic-E, termed as $\mathrm{E}_{m}$. Class 1 of $\mathrm{E}_{m}$ is the instantaneous partially reflecting echo due to a single meteor trail, which has lifetime of minutes at ionosonde frequencies. Class $2 \mathrm{E}_{m}$ is of rare occurrence where meteor shower is sufficiently strong so that 


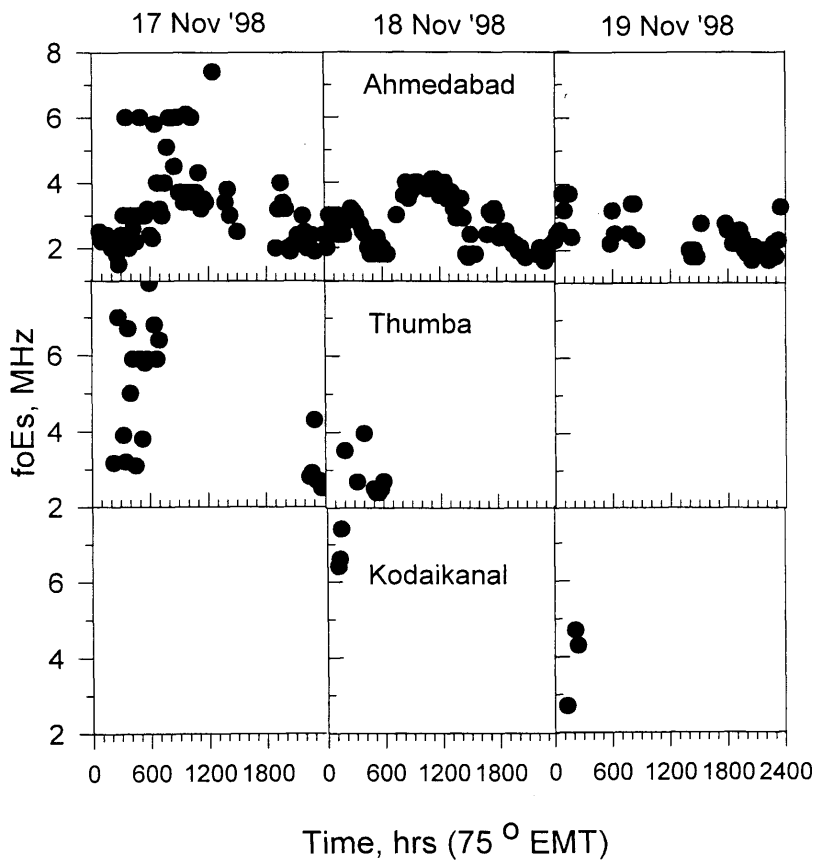

Fig. 10. Daily variations of $f_{0} \mathrm{E}_{s}$ over Ahmedabad, Thumba and Kodaikanal for the period 17-19 November 1998 based on quarter hourly values.

it controls the top frequency of $\mathrm{E}_{s}$ echo on ionogram. Class 3 of $\mathrm{E}_{m}$ is the $\mathrm{E}_{s}$ layers produced by subsequent action of wind shears on residual meteor ion concentration. Goldsbrough and Ellyett (1976) confirmed the correlation of the percentage occurrence of class $1 \mathrm{E}_{m}$ with meteor rate count. From the VHF (49.68 MHz) oblique propagation experiment conducted in Japan during IGY period, Sinno (1979) found intensity of scattering to be correlated with the meteor burst rate. He found that based on daily rate of meteor echoes and daily incidence of sporadic-E, the maximum cross-correlation is seen after a time lag of one week during winter and two weeks during summer. Gupta (1990) reported from in-situ measurements of electron density from Thumba, near the magnetic equator that sharp layers of ionization are preferably present on days with meteoric activity.

Rajaram and Chandra (1991) studied the signatures of the Dhajala meteorite event over the western part of India on the night of 28 January 1976 based on the quarter hourly radio soundings from Ahmedabad. The meteorite event was sighted over Ahmedabad at 2040h. The ionogram at 2045h showed an indication of underlying ionization from the presence of both ordinary and extra-ordinary traces at the lower frequency end of the F-region trace (group retardation). Sporadic-E layer trace at $130 \mathrm{~km}$ was seen at $2100 \mathrm{~h}$. However the ionogram at $2115 \mathrm{~h}$ showed sporadic-E with multiple structures. Three strata separated by about $6 \mathrm{~km}$ were seen both at 2115 and $2130 \mathrm{~h}$. The ionization was thus seen between 120 and $140 \mathrm{~km}$ for nearly an hour and occasionally stratified into several layers. Since the occurrence of night $\mathrm{E}_{s}$ over Ahmedabad during the month of January is not fre- quent (there was no sporadic-E activity during \pm 15 nights in the local time of 20-22h) the sporadic-E layer observed was associated with the Dhajala meteorite event.

The stratified feature of the sporadic-E layers observed both at Ahmedabad and Thumba adds further credence to the meteoric origin of the ionization. Ionization layers during meteor showers have been observed stratified at $5 \mathrm{~km}$ intervals between 100 and $125 \mathrm{~km}$ (McKinley and Millman, 1949). Gupta (1990) observed from Thumba multiple layers of sporadic-E, with semi thickness of $5 \mathrm{~km}$ and separated by $10 \mathrm{~km}$, from the rocket-borne Langmuir probe data on meteor shower days. It is concluded that the strong meteoric shower activity results in the formation of sporadic-E layers. Though the above results indicate the possibility of $\mathrm{E}_{s}$ layers having a close linkage with meteoric activity, there are numerous examples where the results are inconclusive.

The reason for the prevailing ambiguity could be thought of as follows. It is well known that different radio probing techniques like VHF radar and ionosondes respond differently to the structures in the ionosphere. While the VHF radar respond to field aligned irregularities, the ionosondes detect the specular reflections when the probing frequency is less than the critical frequency. However, in certain cases when plasma density irregularities are present in the magnetic equatorial region scatter echoes would be seen far beyond the critical frequency of the layer (the transparent type of sporadic-E, $\mathrm{E}_{S-q}$ ) unlike in the case of blanketing type of sporadic-E layers. These diffuse transparent echoes would be at the same altitude (virtual height) independent of the probing frequency (Figs. 5, 8) and would permit probing of the regions higher above. These irregularities are generated due to plasma instabilities, which operate under certain basic condition in the ambient electric field, and other neutral and electrodynamical parameters. Periods of meteoric activity essentially provide the background plasma density profile mainly constituted of long-lived metallic ions. If the other conditions are not favourable, then the manifestation of these layers as sporadic-E layers in the ionograms might as well not take place. It is well known that the background conditions significantly vary with latitude and therefore similar manifestation need not be seen from different stations, and this would explain the different features observed in the ionograms from Ahmedabad and Thumba/Kodaikanal. Over Ahmedabad, a low latitude station, wind shear mechanism (Axford, 1961; Whitehead, 1961) would be effective due to the finite inclination of the geomagnetic field lines. Longlived metallic ions would be accreted due to the neutral dynamical effects into thin layers of ionization. On the other hand, over Thumba, a dip equatorial station, the wind shear mechanism is rather ineffective. Accretion of ionization has to be necessarily done by means of electrodynamical effects. The polarity of the vertical polarization fields that gets set up at the dip equator (associated with the equatorial electrojet) becomes crucial in this regard. During daytime conditions, under geomagnetic quiet periods, the vertical polarization field is pointing upwards, preventing any sort of accretion of ionization in the E-region, except during counter-electrojet 
periods when the reverse happens (vertical polarization field pointing downwards) which results in the formation of blanketing $\mathrm{E}_{s}$ layer. The diffuse $\mathrm{E}_{s-q}$ type sporadic-E has been explained to be due to the gradient drift instability where in the electron density gradient and the polarization electric fields are in the same direction (Prakash et al, 1971). The multiple traces seen over Thumba in the E-region are hence thought to be due to the presence of discrete long lived layers formed under the special circumstances of meteoric activity, thus enabling the generation of irregularities manifesting as diffuse traces in the ionograms. This could possibly be one of the reasons for the not so good a correlation of the $\mathrm{E}_{S}$ layers with well known meteor showers. Hence, the effect on E-layer ionization, is an interesting aspect calling for an in depth study.

As mentioned earlier, the Leonid meteor shower, the event to which the observations presented in this paper belong to, does happen every year, but peaks every 33 years after the comet Tempel-Tuttle had shed a fresh load of cometary debris for the earth to sail through. As the basic comet orbits in a direction opposite to that of the planets and most other objects in the solar system, it means that the cometary debris released by the comet cut across the earth at a relative speed of $72 \mathrm{~km} / \mathrm{s}$. Such high velocity impact would have other ramifications, in terms of impact, ionization produced, the altitude of deposition, the extent of the plasma cloud generated etc. Though it is the general picture, the ionospheric observations presented in this paper give some clues to the nature of deposition. At the first instance whenever multiple layers are seen in an ionogram it could be due to two possibilities. When the base level $\mathrm{E}_{s}$ layer is of blanketing type in Figs. 8, 9, any additional stratification below the blanketing frequency should necessarily be due to oblique echoes. Where the bottom $\mathrm{E}_{s}$ layer is of transparent type it could also be layering of meteoric debris in the vertical direction. If it is due to the former, i.e. horizontally moving structures, then one would expect the patches to be more or less in the same altitude and drifting overhead. Because of the increased slant distances, the echoes arrive at a later time to manifest itself as an additional stratification over head. For the oblique echoes to be recorded in the ionogram, the patches should be in the field of view or within the beam width of the receiving antenna. When we estimate what should have been the angular separation for the two patches more often located at 120 and 150 $\mathrm{km}$, it turns out to be $36^{\circ}$. With the ionosonde beam width of less than $30^{\circ}$, it is concluded that the patches could not be due to oblique echoes, more so when the height separation is more than $30 \mathrm{~km}$ (Fig. 5, 0320h and 0425h; Fig. 8, 0400h and $0545 \mathrm{~h}$ ). Therefore these patches have to be necessarily due to vertically separated stratification. The multiple layer formation in the altitude region of 100-150 km seen both over Ahmedabad and Thumba during the nights of 17 and 18 November 1998 , seem to indicate that cometary debris, on this occasion, had discretely different impact parameter. Which, as one could envisage, depend on the size and velocity of the given material. Since the relative velocity of the debris need not have discrete values, it is felt that if the debris has certain preferred particle sizes, then it would result in the form of discrete layers of ionization. The prevailing electrodynamical and neutral dynamical forcing could assist these long-lived species into thin layers of ionization. The role played by these forcing is important as the standard meteor radar observations usually traced a large altitude extent of the radio meteor trail, though short lived. The persistence of these layers reveals that the species that constitute the same are long lived and could be subjected to the dynamical forcing. The layers formed are extremely sharp, typically with 1-2 km width, as they manifest in ionograms and the earlier one during the Dhajala event was seen as traces at fixed altitudes. The above observations suggest that these layers represent distinctly different regions of deposition, and it gets confirmed from one of the earlier vapour release experiments from an equatorial station Sriharikota, India (Sridharan et al., 1997). Multiple Barium clouds were released around sunset when the clouds were still exposed to the solar radiation, and thus got ionized. These ionized clouds left traces of discrete layers, which persisted for quite some time as seen in the ionograms exactly at the same height region of the vapour release. This observation could be extrapolated to explain the multiple stratification observed during periods of peak meteoric activity.

Once deposited, the meteoric debris consisting mostly of metallic ions could be converged to form sharp layers of ionization due to the prevailing neutral dynamical and/or electrodynamical conditions, thus providing sharp gradients (though narrow) in density, enabling plasma instability mechanisms to generate plasma density irregularities. The localized irregularities cause the spreading of the echoes in the ionograms. From the above discussion it could be construed that a simple correlation study, without taking into account the prevailing neutral dynamical and electrodynamical forcing and the background conditions of the E-region, would be improper. It is believed that systematic analysis of the past data, following the above arguments, would yield a better picture on the role of meteoric activity in the E-region ionization.

Acknowledgements. This work is supported by the Department of Space, Government of India.

Topical Editor Mark Lester thanks T. Maruyama and M. A. Abdu for their help in evaluating this paper.

\section{References}

Appleton, E. V. and Naismith, R., The radio detection of meteor trails and allied phenomena, Proc. Phys. Soc., 59, 461-472, 1947.

Axford, W. I., Note on a mechanism for the vertical transport of ionization in the ionosphere, Can. J. Phys., 39, 1393-1396, 1961.

Chandra, H., Seasonal and solar cycle variations in the occurrence of night $\mathrm{E}_{S}$ at Ahmedabad, Curr. Sci., 47, 942, 1978.

Ellyet, C. D. and Goldsborough, P. F., Relationship of meteors to sporadic E 1. A sorting of facts, J. Geophys. Res., 81, 61316134, 1976. 
Goldsbrough, P. F. and Ellyett, C. D., Relationship of Meteors to sporadic E 2. Statistical evidence for Class $1 \mathrm{E}_{m}$, J. Geophys. Res., 81, 6135-6140, 1976.

Gupta, S. P., Ionisation layers over the magnetic equator during the meteor shower days, Adv. Space Res., 10, 105-108, 1990.

Jenisskens, P., Meteor stream activity. III. Measurement of the first in a new series of Leonid outburst, Meteoritics \& Planetary Science, 31, 177-184, 1996.

Kinoshita, M., Maruyama, T., and Sagayama, T., Preliminary activity of Leonid Meteor storm observed with a video camera in 1997, Geophys. Res. Lett., 26, 41-44, 1999.

McKinley, D. W. R. and Millman, P. M., A phenomenological theory of radar echoes from meteors, Proc. IRE (Aust.), 37, 364375, 1949.

Milon, D., Observing the 1966 Leonids, J. Brit. Astr. Ass., 77, 8993, 1967.

Prakash, S., Gupta, S. P. and Subbaraya, B. H., Cross field instability and ionization irregularities in the equatorial E region, Nature, 230, 170-171, 1971.
Rajaram, G. and Chandra, H., Sporadic E ionization associated with meteor events, Proc. Ind. Acad. Sci., 100, 255-265, 1991.

Schafer, J. P. and Goodall, W. M., Kennelly-Heavyside layer studies employing a rapid method of visual height determination, Proc. IRE (Aust.), 20, 1941-1945, 1932.

Sinno, K., A role for metallic ions of meteor origin in VHF ionospheric forward scattering and further contribution to the formation of sporadic-E, J. Rad. Res. Lab., 26, 101-116, 1979.

Sinno, K. J., On the time delay of the appearance of sporadic-E following meteor activity, J. Atmosph. Terrest. Phys., 42, 35-39, 1980.

Sridharan, R. et al., Ionization hole campaign-a coordinated rocket and ground-based study at the onset of equatorial spread-F: first results, J. Atmosph. Sol. Terrest. Phys., 59, 2051-2067, 1997.

Whitehead, J. D., The formation of sporadic E layer in the temperate zones, J. Atmosph. Terrest. Phys., 20, 49-58, 1961.

Whitehead, J. D., Production and prediction of sporadic E, Rev. Geophys. Space Phys., 8, 65, 1970. 